\title{
Inhibitory Action of Fungicides on the Sporulation of Piricularia oryzae on the Host Lesions and on the Sponge Matrix
}

\author{
Kazuho MatsuURA* \\ 松浦一穂* : 病斑抢よび sponge matrix 上のいもち病菌胞子形成に \\ 対する殺菌剤の阻害作用
}

\begin{abstract}
The sponge matrix method for obtaining synchronous spores of fungi was applied to the evaluation of sporulation inhibitors as fungicides. Inhibitory activity of a chemical against the sporulation of Piricularia oryzae was studied with simple procedures and estimation and the results obtained by this method allowed kinetic analyses. The relation between the dosage (I) and immersion time $(t)$ required to inhibit 50 per cent of the sporulation was expressed fairly well by the equation $(I)^{n} t=C$, where $n$ and $C$ are constants. The comparison of the results of this method with those of in vivo methods suggested that the inhibition activity of a chemical for practical use was estimated fairly acculately by the sponge matrix test with variation in the immersion time.
\end{abstract}

(Received May 2, 1966)

Researches on the reproduction of fungi are of great economic importance because it is through reproductive bodies that the organisms are able to spread and colonize new substrata. Epidemics of many plant deseases have in fact been caused by the spread of spores produced in quantity on lesions of hosts. Control of reproduction could, therefore, be the control of disease organisms. This idea has been introduced in the evaluation of chemicals as fungicides and some testing methods have been proposed ${ }^{3,6,12)}$. Laboratory tests ${ }^{3,6)}$ require strict procedures in testing and in estimation and results obtained are unfortunately less practical because of the different sporulation pattern on pure cultures from that on natural habitat. On the other hand, a method employing lesions on the host ${ }^{12)}$ is in general more complex and less precise since the environmental conditions are poorly controlled. In the previous paper ${ }^{5)}$, the author reported that the sponge matrix method adequately differentiated the growth and sporulation phase in Piricularia oryzae and that the sporulation pattern on the matrix was similar to that on the host lesions.

In this report, the sponge matrix method was applied to the sporulation inhibition test of $P$. oryzae and results were compared with that of field tests. Some kinetic analyses were made of the inhibition of sporulation by fungicidal agents.

\section{Materials and Methods}

Laboratory test. A strain of Piricularia oryzae (P-18) was used throughout this study. The organism was cultured in the rice-extract medium by the following procedures as was reported in

* Kyoto Herbal Garden, Research and Development Division, Takeda Chemical Industries Ltd. Kyoto, Japan. 武田藥品研究開発本部京都試験農園 
the previous paper ${ }^{5)}$. Fifty pieces of sponge matrices and $100 \mathrm{ml}$ of the medium were put into a $300-\mathrm{m} l$ shaking flask, sterilized and inoculated with $2 \mathrm{~m} l$ of spore suspension of P. oryzae $\left(5 \times 10^{5}\right.$ spores per $\mathrm{ml}$ ). The inoculated flasks were incubated for 4 days at $28^{\circ} \mathrm{C}$ on a reciprocal shaker. During this submerged culture, the mycelia reached full growth in the sponge matrices. Ten pieces of sponge matrix were then immersed in $10 \mathrm{ml}$ of aqueous solution of fungicides for a certain period, washed with water to remove fungicides and kept in a moist chamber at $28^{\circ} \mathrm{C}$. Twenty four hours later the spores of the fungus were counted by a haemacytometer and the inhibitory activity, I, of chemicals against the sporulation was calculated by the following formula,

$$
I=\left(1-\frac{N}{N_{0}}\right) \times 100 \quad(\%)
$$

where $\mathrm{N}$ and $\mathrm{N}_{0}$ represent the number of spores on the sponge matrix respectively with and without addition of test substance. The tests were repeated 4 times.

Greenhouse test. Seedlings of rice plants (Asahi-4, 25-day-old) were inoculated with approximately $1 \mathrm{~m} l$ of the spore suspension per plant $\left(5 \times 10^{5}\right.$ spores per $\left.\mathrm{m} l\right)$, kept in a moist chamber for 24 hours at $28^{\circ} \mathrm{C}$ and then maintained in a greenhouse with high relative humidity. Approximately $2 \mathrm{~m} l$ of solution of the test chemicals were sprayed on each test plant four days after the inoculation (before initiation of sporulation). Then the leaves were detached from the stems, cut into pieces about $5 \mathrm{~cm}$ long and kept in a moist chamber at $28^{\circ} \mathrm{C}$ for 48 hours. Thirty lesions were subjected to microscopic observation in each treatment and tests were repeated 11 times. The degree of sporulation was estimated by the following indices:

$\begin{array}{cc}\text { Index } & \text { Degree of sporulation against control } \\ 5 & \text { over } 80 \text { per cent } \\ 4 & \text { over } 60 \text { per cent } \\ 3 & \text { over } 40 \text { per cent } \\ 2 & \text { over } 20 \text { per cent } \\ 1 & \text { below } 20 \text { per cent } \\ 0 & \text { no sporulation }\end{array}$

and the inhibitory activity, I, was calculated by the formula (2),

$$
I=\left(1-\frac{\sum \mathrm{DN}}{5 \mathrm{~N}_{0}}\right) \times 100 \quad(\%)
$$

where $\mathrm{N}_{0}$ stands for the total number of lesions, $\mathrm{D}$ for the index and $\mathrm{N}$ for the number of lesions belonging to the index $D$.

Field test. The same strain of rice plant used in the greenhouse test was cultivated under field conditions in 1/2000a Wagner's pots until the stage of maximum tillering (a) and maturing stage of grains (b). Varieties susceptible to the rice blast disease, Moko and Nureba, were also cultivated in the pots, inoculated with spore suspension of $P$. oryzae before the stage (a) and placed among the test plants to enhance natural infection. The inhibition test of fungicides against sporulation on leaves was made at the stage (a), and the inhibition against sporulation on lesions produced at necks of ears was tested at the stage (b). Twenty $\mathrm{ml}$ of fungicide solution was applied to five plants. Tests were repeated 6 times. Testing procedures were the same as those in greenhouse test.

The following fungicides were used in this experiments:

antimycin $\mathrm{A}(\mathrm{AmA})$

blasticidin $\mathrm{S}(\mathrm{BcS})$

Phenylmercuric dinaphthylmethane disulphonate (PMF) 
Phenylmercuric acetate (PMA)

$\mathrm{BcS}, \mathrm{PMF}$ and PMA were dissolved in water and $\mathrm{AmA}$ was suspended in 1 per cent aqueous solution of ethyl alcohol.

\section{Results}

The patterns of spore formation of Piricularia oryzae are different depending on the ways of culturing. It was previously pointed out that the sporulation of this organism was more rapid on the sponge matrix than on the agar slant5). On the lesions of blast disease of rice plants, conidia are produced in quantity during the night, provided that the weather conditions are favorable. Therefore, the time required for the maximum sporulation of P. oryzae was determined on the sponge matrix, on the agar medium and on the lesions of rice seedlings (Fig. 1).

On the sponge matrix, the sporulation reached the maximum within a day, while on the agar medium, the maximum number of spores was observed 7 days after the initial sporulation. The spore formation on the host lesions was similar to that observed on the sponge matrix, but required two days for reaching the maximum. The initial spores were observed both on the sponge matrix and on the lesions six hours after being transfered in a moist chamber.

Laboratory test. The mycelia in the sponge matrix set to sporophore development when exposed to air after finishing the submerged culture. The mycelia were treated by immersing in an aqueous solution of fungicides before the sporophore formation initiated. As the immersion time was supposed to affect the inhibitory activity of chemicals to the sporulation, the effects of immersion time and dosages on the activity were studied and the results were shown in Fig. 2. A simple plot of per

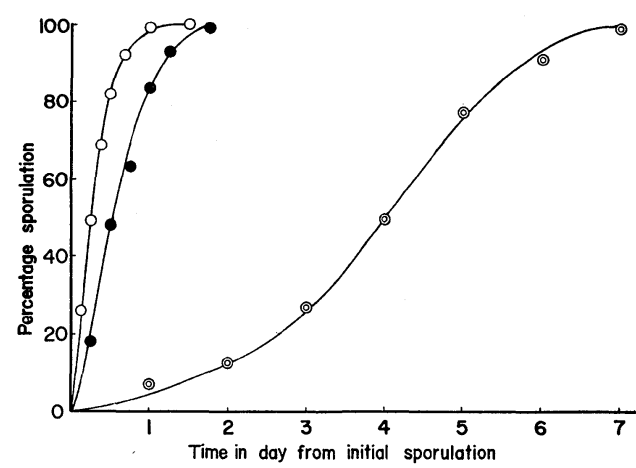

Fig. 1. Sporulation of $P$. oryzae on sponge matrix (O), agar medium (O) and on seedling-lesions (•).

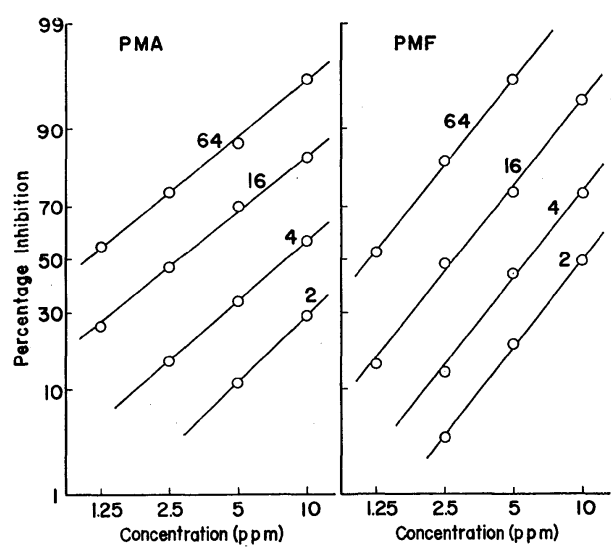

(1)

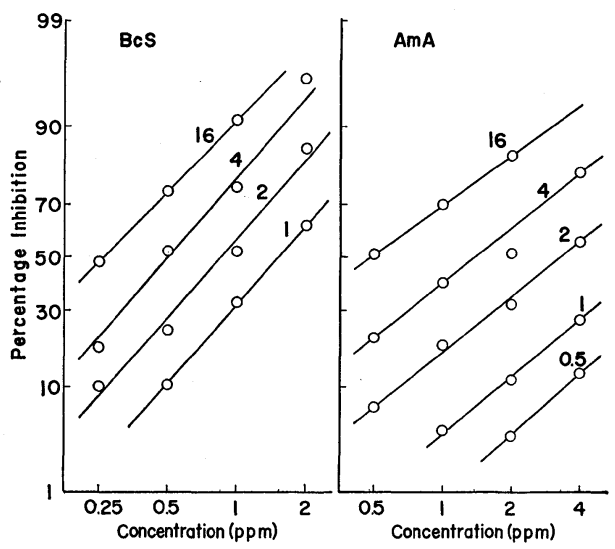

(2)

Fig. 2. Dosage-response curves for the inhibition of sporulation of $P$. oryzae on sponge matrix by various fungicides as a function of immersion times $(0.5,1,2,4,16,64$ minutes $)$. 
cent inhibition against fungicide concentration or the logarithm of concentration yielded a sigmoid curve. This was converted to a straight line on a logarithmic-probability paper, since resistance in a population to a toxic agent is generally distributed normally with respect to the logarithm of the dose $\mathrm{e}^{1,4)}$. The immersion time in a fungicide solution was reflected on the slope and the intercept of a dosage-response curve. The slopes of each immersion time, i.e., $1 / \log \left(\mathrm{ED}_{84} / \mathrm{ED}_{50}\right)^{8)}$, of these curves ranged from approximately 2.3 to 2.9 on PMF and 2.3 to 2.8 on $\mathrm{BcS}$. But the resultant value for the concentration required to prevent sporulation by 50 per cent, $\mathrm{ED}_{50}$, varied considerably with the differences of fungicides and immersion times (Table 1).

It will be noted in Table 1 that the relation between the dosage (I) and the time $(t)$ required for 50 per cent inhibition of sporulation was expressed fairly well by the equation ( $I)^{n} t=C$, where $n$ and $C$ are constants, and the plots of $\log t$ against $\log$ (I) are straight lines as shown in Fig. 3 .

The relation between the concentration of the fungicide and the time required to produce the effect will be described later in conjunction with correlation with the results of a greenhouse and field tests.

Greenhouse test. The effect of $\mathrm{BcS}$ and PMF on the sporulation on seedling lesions is shown in Fig. 4. The data can also be plotted as a straight line on a logarithmic-probability paper. BcS showed $96.7 \pm 1.9$ per cent inhibition at the concentration of $20 \mathrm{ppm}$ and $94.0 \pm 2.6$ per cent at $10 \mathrm{ppm}$. The $\mathrm{ED}_{84}$ value was found to be 3.2 ppm. PMF inhibited the spore formation by $91.1 \pm 6.8$ per cent at $20 \mathrm{ppm}$ (as $\mathrm{Hg}$ ) and $82.0 \pm 9.9$ per cent at $10 \mathrm{ppm}$. At least $12 \mathrm{ppm}$ was necessary for $84 \mathrm{per}$ cent inhibition of sporulation. The slopes of the dosage-response curves were 1.1 on $\mathrm{BcS}$ and 1.7 on PMF. It was observed in the course of this test that almost no conidiophores but aerial mycelia were formed on the lesions treated with $20 \mathrm{ppm}$ of $\mathrm{BcS}$, while both conidiophores and aerial mycelia were considerably developed on the lesions treated with $20 \mathrm{ppm}$ of PMF.

Field tests. It is generally accepted that under natural conditions conidia produced on lesions of leaves cause the epidemic of neck-blast disease, which gives the most serious damage to the yield of rice. Thus both the lesions of leaves and necks of the plant were employed as a test material. The inhibitory effects of $\mathrm{BcS}$ and PMF on the sporulation on the leaf-and neck-lesions are shown in Fig. 5 in the form of dosage-response curve. $\mathrm{BcS}$ at the concentration of $20 \mathrm{ppm}$ 


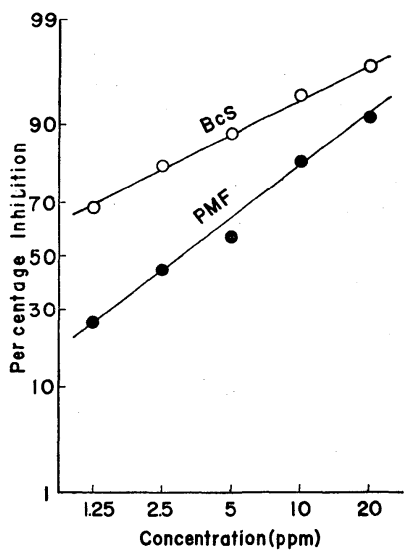

Fig. 4. Dosage-response curves for the inhibition of sporulation of $P$. oryzae on seedling-lesions by various fungicides.

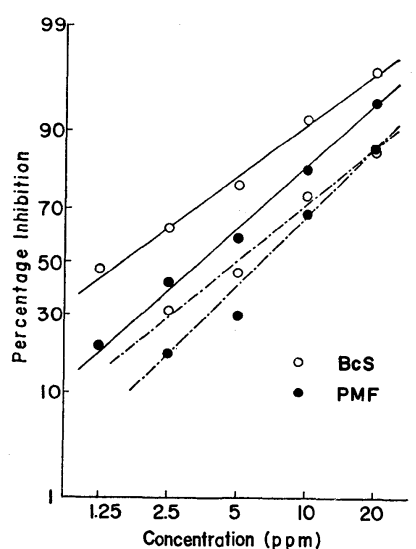

Fig. 5. Dosage-response curves for the inhibition of sporulation of $P$. oryzae on leaf-(-) and necklesions (-.--) by various fungicides.

gave $96.8 \pm 3.2$ per cent inhibition of the sporulation on leaf-lesions and $85.9 \pm 9.1$ per cent inhibition on neck-lesions. The $\mathrm{ED}_{84}$ value was found to be $6.1 \mathrm{ppm}$ on the leaf-lesions and $16.9 \mathrm{ppm}$ on the neck-lesions. The slope of the plotting of the leaf-test was 1.7 , while that of the neck-test was 1.9. PMF, at $20 \mathrm{ppm}$, showed $94.0 \pm 5.1$ per cent inhibition on the leaf and $86.8 \pm 10.2$ per cent on the neck-lesions. The $\mathrm{ED}_{84}$ value was 10.8 and the slope was 2.0 in the test of leaf-lesions, while the value was 17.3 and the slope was 2.2 in the test of necklesion. Thus, the slopes and $\mathrm{ED}_{84}$ clearly indicated that the sporulation inhibition of $\mathrm{BcS}$ and PMF on neck-lesions appeared to be less effective than that on leaf-lesions.

\section{Discussion}

Epidemics of fungal diseases of plants are often caused by the spread of reproductive structures. A sporulation inhibitory activity of a chemical, therefore, has been considered to be one of the principal factors which contributes to a high controlling effect against plant diseases, as was shown in the prevention of spread of the rice blast fungus (Piricularia oryzae) by blasticidin $\mathrm{S}^{6)}$ and organomercuric fungicides.

However relatively minor effort has been made in the evaluation of fungicides as a function of sporulation inhibition, although some methods have been proposed in the study of the modes of action of blasticidin $\mathrm{S}^{6)}$ and antimycin $\mathrm{A}^{3)}$. According to the method of Misato et. al. ${ }^{6)}$, mycelia of $P$. oryzae on an agar medium were immersed in the aqueous solution of $\mathrm{BcS}$ for a certain period and washed with water to remove $\mathrm{BcS}$. A similar attempt was made by Harada et. al..$^{3)}$ in the investigation of AmA. Yamada et. al. reported that inhibitory effects of fungicides on the sporulation of Alternaria kikuchiana could be studied on the lesions of leaves of Japanese pear ${ }^{12)}$. It is desirable that the host lesions be employed as a material in the inhibition test of sporulation, but it is time-consuming, laborious and less precise. The sporulation of $P$. oryzae on an agar medium was considerably different from that on natural habitat, as shown in Fig. 1. Besides, strict procedures were required in the application of chemicals and in the estimation of inhibitory activities. Results obtained by the test of pure cultures by Misato et. al. ${ }^{6)}$ and Harada et. al. ${ }^{3)}$ could possibly be interpreted as effects of fungicides on the mycelial growth rather than on 
the sporulation. A major barrier to establishing laboratory tests for sporulation inhibition is the lack of the appropriate experimental method to discriminate adequately between the growth and the sporulation. The sponge matrix method allowed fungi to make an adequate switchover from vegetative growth to sporulation and the spores were formed synchronously ${ }^{5}$. This method was applied to the inhibition test of sporulation of $P$. oryzae with simple procedures and estimation. Inhibition of sporulation on the sponge matrix was affected by the dosage and the immersion time in the fungicide solution. The relation between the dosage (I) and the time $(t)$ required for 50 per cent inhibition of sporulation was pointed out to fit fairly well the equation $(I)^{n} t=C$, where $n$ and $C$ are constants. The marked differences in the rate of inhibition and the potencies of these fungicides are well illustrated by these constants in the equation ${ }^{11)}$. As $n$ increases, the curves approach more rapidly the (I) axis. The values of $n$ and $C$ may be determined by many factors, for instance, affinity of the agent to the surface of cells, permiability, reaction with the enzymes and the subsequent processes leading to the inhibition of sporulation. The equations of the concentration-time curves for inhibition by the fungicides tested are as follows:

$$
\begin{array}{cl}
\mathrm{PMF} ; \quad(\mathrm{I})^{1.67} t=85.9 \\
\mathrm{PMA} ; \quad(\mathrm{I})^{1.30} t=72.8 \\
\mathrm{BcS} ; \quad(\mathrm{I})^{1.32} t=1.66 \\
\mathrm{AmA} ; \quad(\mathrm{I})^{1.893} t=5.72
\end{array}
$$

This type of equation has been introduced to the analyses of toxicity of insecticides ${ }^{7,9)}$, copper ion on Nitella $a^{2)}$ and arsenicals on trypanosomes ${ }^{11}$.

The $\mathrm{ED}_{50}$ values of $\mathrm{BcS}$ and $\mathrm{PMF}$ in vivo were summarized inTable 2. The immersion time required for 50 per cent inhibition of sporulation in vitro at the same concentration as in vivo was calculated from the equation presented above and also shown in Table 2. PMF gave the $\mathrm{ED}_{50}$ value at the concentration of $3 \mathrm{ppm}$ on the seedling lesions. This concentration of PMF needed approximately 14 minutes to prevent the sporulation of 50 per cent on the sponge matrix. In the field tests, the inhibitory effect of PMF on the spore formation appeared weaker, so the immersion time of the sponge matrix should be reduced to obtain a similar result of inhibition. The same tendency was also found in the inhibition of BcS against sporulation.

The slopes of the dosage-response curves in vivo tests ranged approximately from 1.7 to 2.2 on PMF and from 1.1 to 1.9 on $\mathrm{BcS}$, while that in vitro, from 2.3 to 2.9. Some noticeable differences in the dosage-responses of the sporulation on the host lesions and on the matrix might probably be caused by the differences in treating methods of chemicals, in estimation, and also in the rates of decomposition due to many factors ${ }^{10)}$, such as light, oxidation, sulfhydryl com-

Table 2. $\mathrm{ED}_{50}$ values in the greenhouse- and the fieldtests and immersion times required to prevent 50 per cent of the sporulation of $P$. oryzae on the sponge matrix at the concentration of $\mathrm{ED}_{50}$ of in vivo tests.

\begin{tabular}{c|l|c|c}
\hline \hline Chemical & Material & $\mathrm{ED}_{50}(\mathrm{ppm})$ & $\begin{array}{l}\text { Time required to prevent 50 per } \\
\text { cent of sporulation on the sponges } \\
\text { at the concentration of (a) }\end{array}$ \\
\hline \multirow{3}{*}{ PMF } & seedling-lesions & $3.0(\mathrm{a})$ & $13.9 \mathrm{~min}$. \\
& leaf-lesions & 3.4 & 11.3 \\
& neck-lesions & 6.1 & 4.3 \\
\hline \multirow{3}{*}{$\mathrm{BcS}$} & seedling-lesions & 0.4 & 5.5 \\
& leaf-lesions & 1.6 & 0.9 \\
& neck-lesions & 4.9 & 0.2 \\
\hline
\end{tabular}


pounds in the hosts.

It may be concluded that, even though the dosage-response curve of the sponge matrix method is not in accord precisely with that of greenhouse and field tests, this method is convenient for and applicable to the sporulation inhibition test of antiblast agents. Kinetic analyses made of several fungicidal agents substantiated the precision and efficacy of this method. Effectiveness of chemicals suggested for use as fungicides could be tested simply by varying the immersion time.

\title{
Acknowledgement
}

The author wishes to express his thanks to Professor Dr. S. Akai, Kyoto University, for his valuable advice and criticism, and to Mr. S. Ouchi, Kyoto University, for his helpful suggestions. The author is also indebted to Dr. S. Tatsuoka, Director of the Division, to Dr. I. Tanaka, Advisor of the Laboratory, to Mr. R. Hatta, Dr. T. Kobayashi and Mr. I. Sumina, in the author's laboratory, for their guidance and criticism during the entire project.

\section{Literature cited}

1. Bliss, C.I. (1935). Ann. Appl. Biol. 22: 134-167.

2. Cook, S.F. (1926). J. Gen. Physiol. 9: 735-741.

3. Harada, Y., Kumabe, K., Kagawa, T. and Sato, Y. (1959). Ann. Phytopath. Soc. Japan 24: $247-254$

4. Horsfall, J.G. (1956). Principles of Fungicidal Action. Waltham, Mass. pp. 15-29.

5. Matsuura, K. (1965). Ann. Rept. Takeda Res. Lab. 24: 266-272.

6. Misato, T., Okimoto, Y., Ishii, I., Asakawa, M. and Fukunaga, K. (1959). Ann. Phytopath. Soc. Japan 24: 307-312.

7. Nagasawa, S. and Takano, T. (1950). Botyû-Kagaku 15: 46-53.

8. Rich, S. and Horsfall, J. G. (1952). Phytopath. 42: 457-460.

9. Suwanai, M. (1957). Bullet. Nat. Inst. Agric. Sci. C-7: 113-147.

10. Tatsuyama, K. and Akai. S. (1965). Botyû-Kagaku 30: 96-103.

11. Webb. J. L. (1963). Enzyme and Metabolic Inhibitors. New York and London, pp. 598-603.

12. Yamada, S. and Kishi, K. (1959). J. Hortic. Assoc. Japan 24: 41-50.

\section{和文摘要}

\author{
病斑括よび sponge matrix 上のいもち病菌胞子形成に \\ 対する殺菌剤の阻害作用
}

松 浦 一 穗

synchronous spore を得る目的で確立した sponge matrix 法を胞子形成阻害試験に応用した。この方法 によればいもち病菌 Piricularia oryzae の胞子形成に対する各種殺菌剂の阻害作用が容易に判定でさる。薬 量 $(I)$ と胞子形成を $50 \%$ 阻害するに要する浸漬時間 $(t)$ との関係は, 式 $(I)^{n} t=C(n C$ は定数 $)$ にく 適合することが判明した。

この結果を, 温室内括よび國場での宿主体の病斑を用いた試験結果と比較してみると, sponge matrix 試 験の浸漬時間を変えることにより，宿主体病斑の胞子形成に与える殺菌剤の影響を類推することがでさた。 